\title{
Mutation in one Molecule Induces Beating Rate Changes by Affecting the Coupled Clock Pacemaker Function
}

Yael Yaniv* and Joachim A Behar

Biomedical Engineering Faculty, Technion-IIT, Israel

Submission: July 07, 2017; Published: July 26, 2017

*Corresponding author: Yael Yaniv, Laboratory of Bioenergetic and Bioelectric Systems, Biomedical Engineering Faculty, Technion-IIT, Haifa, Israel, Tel: 972-4-8294124 ; Fax: 972-4-8294599; Email: yaely@bm.technion.ac.il

\begin{abstract}
Pacemaker function is orchestrated through molecules on the membrane and on the sarcoplasmic reticulum that are coupled by $\mathrm{Ca}^{2+}$ and post-translation modification signaling. These molecules and signaling cascades form one coupled-clock system. Experimental and computational evidence highlight the coupling between components in this system. However, most studies examine how a given pacemaker mutation causes bradycardia or tachycardia and report changes only for the affected molecule without capturing the overall effect on the coupled-clock system. Here, we provide our opinion on how a mutation in one molecule impacts the beating rate by affecting the coupled clock pacemaker function (and thus not only a single molecule). A better understanding of changes in the coupled-clock system due to a given pacemaker mutation may provide new insights into the changes in physiological processes in health and disease and support the design of new drug therapeutics for treating cardiac conditions.
\end{abstract}

Keywords: Arrhythmia; Funny current; Protein kinase A

\section{Introduction}

The sinoatrial node consists of hundreds of pacemaker cells that initiate the heartbeat. Evidence has shown that pacemaker cell function is orchestrated not only by one molecule, but through molecules on the membrane and on the sarcoplasmic reticulum that are coupled by $\mathrm{Ca}^{2+}$ and post-translation modification signaling (reviewed in [1]). These molecules and their associated coupling nodes create the coupled-clock system that controls pacemaker function. Both experimental $[2,3]$ and computational [4-6] evidence confirm the theory that any change in the function of any membrane or intracellular molecule should indirectly affect the function of the other molecules, and that the state of the ensemble of molecules should determine the pacemaker cells' beating rate. With the recent advances in gene research and the ability to identify mutations in membrane and intracellular molecules, mutations have been associated with several cardiac diseases $[7,8]$. Several groups have identified mutations in pacemaker cells involved in either bradycardia or tachycardia. Hategan et al. [9] reported that the $\mathrm{HCN}_{4}$ mutation c. $1737+1 \mathrm{G}>\mathrm{T}$ leads to bradycardia, which they interpreted to exist only by reduction in $\mathrm{I}_{\mathrm{f}}$ through altered cAMP binding to $\mathrm{HCN}_{4}$. Similarly, Biel et al. [10] reported that the $\mathrm{HCN}_{4}$ mutation V492F leads to Brugada syndrome. The HEK293 cell line that expressed this mutation showed that $\mathrm{I}_{\mathrm{f}}$ was responsive to cAMP, but required a more negative voltage for activation. These authors also concluded that "modulation of $\mathrm{HCN}_{4}$ activity could be the cause of the diagnosed cardiac abnormality". Finally, Duhme et al. have shown that the $\mathrm{HCN}_{4}$ mutation $\mathrm{K} 530 \mathrm{~N}$ is associated with ventricular tachyarrhythmia. The HEK293 cell line that expressed this mutation showed a shift in the halfmaximal activation voltage of $I_{\mathrm{f}}$. The authors concluded that "f-channel dysfunction contributes to the development of a trial tachyarrhythmia". However, mutation in $\mathrm{HCN}_{4}$ also alters other mechanisms of the coupled-clock system, which together change the heart rhythm [3,4,11]. At the single cell level, experimental and computational evidence have shown that blocking $I_{\mathrm{f}}$ by ivabradine increases the beating interval [3] and beating rate variability [11], not only through the direct effect of the $\mathrm{I}_{\mathrm{f}}$ current, but through changes in $\mathrm{Ca}^{2+}$ signaling and $\mathrm{I}_{\mathrm{NCX}}$. Further computational evidence has shown that mutations that increase cAMP binding to $\mathrm{HCN}_{4}$ or alter $\mathrm{V}_{1 / 2}$ lead to tachycardia and bradycardia, respectively, by the afferent mechanisms and changes in post-translation modification signaling [4]. Thus, both the direct effect on the mutant $\mathrm{HCN}_{4}$ and the indirect effect on other coupled-clock molecules lead to either bradycardia or tachycardia. 
Not only have mutations in $\mathrm{HCN}_{4}$ been associated with bradycardia or tachycardia. Glukhov et al. [12] have shown that mutations in Calsequestrin 2 lead to loss of pacemaker function. The authors concluded that mutations in Calsequestrin 2 lead to fibrosis and altered $\mathrm{Ca}^{2+}$ signaling. Additionally, the Gómez lab has shown that mutations in the ryanodine channel (either R4496C or R420Q) are involved in catecholaminergic polymorphic ventricular tachycardia [13,14]. Although, both groups explored the mutation in one molecule, in contrast to the former groups they documented other altered mechanisms that together led to arrhythmogenic episodes. Similar to the $\mathrm{HCN}_{4}$ case, mutation in intracellular molecules also alter other mechanisms of the coupled-clock system, which together change the heart rhythm.

\section{Conclusion}

There is no "one important molecular determinant of heart rate regulation," but rather interaction among coupled-clock molecules, which define the heart rate and rhythm. Direct pharmacological treatments that affect cAMP binding to $\mathrm{HCN}_{4}$ or restore $\mathrm{I}_{\mathrm{f}}$ do not exist. Similarly, drugs to compensate for the loss of Calsequestrin 2 or efficiently restore ryanodine function do not exist. However, it may be possible to restore the pacemaker function by using drugs that will alter other pacemaker clock molecules or coupling nodes, thus re-establishing the normal coupling between the two pacemaker clocks.

\section{Acknowledgment}

The work was supported by the NSFC-ISF Joint Research Program, No. 398/14 (Y.Y), the Israel Ministry of Science (Y.Y), an Aly-Kaufman Postdoctoral Fellowship (JB), and The Center for Absorption in Science, Ministry of Immigrant Absorption, and State of Israel (JB).

\section{References}

1. Yaniv Y, Lakatta EG, Maltsev VA (2015) From two competing oscillators to one coupled-clock pacemaker cell system. Front Physiol 6: 28.

2. Yaniv Y, Lakatta EG (2013) Pacemaker gene mutations, bradycardia, arrhythmias and the coupled clock theory. J Cardiovasc Electrophysiol 24(12): E28-E29.

3. Yaniv Y, Sirenko S, Ziman BD, Spurgeon HA, Maltsev VA, et al. (2013) New evidence for coupled clock regulation of the normal automaticity

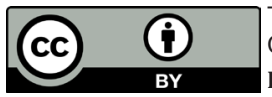

This work is licensed under Creative Commons Attribution 4.0 License DOI: $10.19080 /$ JOCCT.2017.06.555695 of sinoatrial nodal pacemaker cells: bradycardic effects of ivabradine are linked to suppression of intracellular $\mathrm{Ca}^{2+}$ cycling. J Mol Cell Cardiol 62: 80-89.

4. Behar J, Yaniv Y (2016) Dynamics of PKA phosphorylation and gain of function in cardiac pacemaker cells: a computational model analysis Am J Physiol Heart Circ Physiol 310(9): H1259-H1266.

5. Behar J, Ganesan A, Zhang J, Yaniv Y (2016) The Autonomic Nervous System Regulates the Heart Rate through cAMP-PKA Dependent and Independent Coupled-Clock Pacemaker Cell Mechanisms. Front Physiol 7: 419.

6. Maltsev VA, Yaniv Y, Maltsev AV, Stern MD, Lakatta EG (2014) Modern perspectives on numerical modeling of cardiac pacemaker cell. J Pharmacol Sci 125(1): 6-38.

7. Ablorh N-AD, Thomas DD (2015) Phospholamban phosphorylation, mutation, and structural dynamics: a biophysical approach to understanding and treating cardiomyopathy. Biophysical Reviews $7(1): 63-76$

8. Yamashita T, Sekiguchi A, Iwasaki YK, Sagara K, Iinuma H, et al. (2003) Circadian variation of cardiac K+ channel gene expression. Circulation 107(14): 1917-1922.

9. Hategan L, Csányi B, Ördög B, Kákonyi K, Tringer A, et al. (2017) A novel "splice site" $\mathrm{HCN}_{4}$ Gene mutation, c.1737+1 G\&gt;T, causes familial bradycardia, reduced heart rate response, impaired chronotropic competence and increased short-term heart rate variability. International journal of cardiology. 15(241): 364-372..

10. Biel S, Aquila M, Hertel B, Berthold A, Neumann T, et al. (2016) Mutation in S6 domain of $\mathrm{HCN}_{4}$ channel in patient with suspected Brugada syndrome modifies channel function. Pflugers Arch 468(10): 1663-1671.

11. Yaniv Y, Lyashkov AE, Sirenko S, Okamoto Y, Guiriba TR, et al. (2014) Stochasticity intrinsic to coupled-clock mechanisms underlies beatto-beat variability of spontaneous action potential firing in sinoatrial node pacemaker cells. J Mol Cell Cardiol 77: 1-10.

12. Glukhov AV, Kalyanasundaram A, Lou Q, Hage LT, Hansen BJ, et al. (2015) Calsequestrin 2 deletion causes sinoatrial node dysfunction and atrial arrhythmias associated with altered sarcoplasmic reticulum calcium cycling and degenerative fibrosis within the mouse atrial pacemaker complex1. Eur Heart J 36(11): 686-697.

13. Neco P, Torrente AG, Mesirca P, Zorio E, Liu N, et al. (2012) Paradoxical effect of increased diastolic $\mathrm{Ca}(2+)$ release and decreased sinoatrial node activity in a mouse model of catecholaminergic polymorphic ventricular tachycardia. Circulation 126(4): 392-401.

14. Wang YY, Mesirca P, Marqués-Sulé E, Zahradnikova A, Villejoubert O, et al. (2017) RyR2R420Q catecholaminergic polymorphic ventricular tachycardia mutation induces bradycardia by disturbing the coupled clock pacemaker mechanism. JCI Insight 20(8).

\section{Your next submission with Juniper Publishers will reach you the below assets}

- Quality Editorial service

- Swift Peer Review

- Reprints availability

- E-prints Service

- Manuscript Podcast for convenient understanding

- Global attainment for your research

- Manuscript accessibility in different formats

( Pdf, E-pub, Full Text, Audio)

- Unceasing customer service

Track the below URL for one-step submission https://juniperpublishers.com/online-submission.php 